\title{
Escherichia coli is unable to produce pyrroloquinoline quinone (PQQ)
}

\author{
K. Matsushita, ${ }^{2}$ J. C. Arents, ${ }^{1}$ R. Bader, ${ }^{1}$ M. Yamada, ${ }^{2}$ O. Adachi ${ }^{2}$ \\ and P. W. Postma ${ }^{1}$
}

Author for correspondence: P. W. Postma. Tel: +31 20525 5112. Fax: +31 205255124.

e-mail: postma@chem.uva.nl

1 E. C. Slater Instituut, BioCentrum, University of Amsterdam, Amsterdam, The Netherlands

2 Department of Biological Chemistry, Faculty of Agriculture, Yamaguchi University, Yamaguchi, Japan
Many bacteria can synthesize the cofactor pyrroloquinoline quinone (PQQ), a cofactor of several dehydrogenases, including glucose dehydrogenase (GCD). Among the enteric bacteria, Klebsiella pneumoniae has been shown to contain the genes required for $\mathrm{PQQ}$ biosynthesis. Escherichia coli and Salmonella typhimurium were thought to be unable to synthesize PQQ but it has been reported that strain EF260, a derivative of $E$. coli FB8, can synthesize PQQ after mutation and can oxidize glucose to gluconate via the GCD/PQQ pathway (F. Biville, E. Turlin \& F. Gasser, 1991, J Gen Microbiol 137, 1775-1782). We have reinvestigated this claim and conclude that it is most likely erroneous. (i) Strain EF260, isolated originally by Biville and coworkers, was unable to synthesize a holo-enzyme GCD unless PQQ was supplied to the growth medium. No GCD activity could be detected in membrane fractions. (ii) The amount of PQQ detected in the growth medium of EF260 was very low and not very different from that found in a medium with its parent strain or in a medium containing no cells. (iii) EF260 cells were unable to produce gluconate from glucose via the PQQ/GCD pathway. (iv) Introduction of a gcd:: Cm deletion in EF260, eliminating GCD, did not affect glucose metabolism. This suggested a pathway for glucose metabolism other than the PQQ/GCD pathway. (v) Glucose uptake and metabolism in EF260 involved a low-affinity transport system of unknown identity, followed most likely by phosphorylation via glucokinase. It is concluded that $E$. coli cannot synthesize PQQ and that it lacks genes required for PQQ biosynthesis.

Keywords: glucose dehydrogenase, $\mathrm{PQQ}$, Escherichia coli, quinoprotein, glucose metabolism

\section{INTRODUCTION}

Pyrroloquinoline quinone (PQQ) is an important cofactor of bacterial dehydrogenases, linking the oxidation of many different compounds to the respiratory chain. PQQ was the first of the class of quinone cofactors that have been discovered in the last 18 years and make up the prosthetic group of quinoproteins (for reviews, see Duine, 1991; Klinman, 1996; Klinman \& Mu, 1994).

The quinoprotein glucose dehydrogenase (GCD) has been demonstrated in a number of micro-organisms including the enteric bacteria Klebsiella pneumoniae, Escherichia coli and Salmonella typhimurium, and in

Abbreviations: GCD, glucose dehydrogenase; PQQ, pyrroloquinoline quinone.
Acinetobacter, Pseudomonas, Agrobacterium and Gluconobacter species. In most cases, GCD is a membrane-bound enzyme which oxidizes glucose to gluconate in the periplasmic space (for a review, see Duine, 1991). The formed gluconate is subsequently taken up in a number of these organisms via a specific transport system and further metabolized. The reducing equivalents from glucose are donated via PQQ to the respiratory chain. Surprisingly, in some of the organisms mentioned only apo-GCD is found. Thus, $K$. pneumoniae synthesizes a holo-GCD (Neijssel et al., 1983 ) but the closely related $E$. coli and $S$. typhimurium can synthesize only apo-GCD but not PQQ (Hommes et al., 1986, 1984). However, apo-GCDs in these and other organisms can be converted into active holo-GCDs by the addition of extracellular PQQ (Ameyama et al., 1986; Hommes et al., 1986, 1984; Van Schie et al., 1987). 
It has been concluded that organisms like $E$. coli and $S$. typhimurium lack the genes to synthesize PQQ and it remains unclear what the role of such apo-GCDs could be. It has been suggested that organisms that are unable to synthesize PQQ could scavenge it from their surroundings and activate their apo-quinoproteins (Matsushita \& Adachi, 1993).

Genes involved in PQQ biosynthesis have been cloned, sequenced and characterized from a number of microorganisms. For instance, six $p q q$ genes, $p q q A B C D E F$, have been found and sequenced in $K$. pneumoniae (Meulenberg et al., 1992). pqq genes have also been found in Acinetobacter calcoaceticus (Goosen et al., 1989), Methylobacterium extorquens (Morris et al., 1994; Springer et al., 1996; Toyama et al., 1997), Pseudomonas fluorescens (Schnider et al., 1995) and Methylobacillus sp. (GenBank L78064). The enzymes encoded by the corresponding $p q q$ genes are highly conserved between the various species but only in one case, K. pneumoniae PqqF (see below) and the comparable M. extorquens protein, has extensive homology with other proteins in the database been found.

The biosynthetic route of PQQ has not been elucidated yet, but it has been proposed that glutamate and tyrosine are precursors of PQQ (Houck et al., 1988, 1991; Van Kleef \& Duine, 1988). In all cases studied, the $p q q$ operon contains a small gene; in the case of $K$. pneumoniae, this is $p q q A$ which can encode a small peptide of 23-29 aa containing a glutamate and tyrosine residue at conserved positions. Synthesis of the small peptide has been demonstrated (Velterop, 1995) and it is thought to be the precursor of PQQ (Goosen et al., 1989, 1992; Meulenberg et al., 1992). The K. pneumoniae $p q q F$ gene product shows similarity to proteases like E. coli protease III (or pitrilysin) and insulinases and it has been proposed that the PqqF enzyme is involved in cleavage of the PqqA precursor (Meulenberg et al., 1992).

Expression of the six K. pneumoniae pqq genes in E. coli results in PQQ synthesis and an active GCD (Meulenberg et al., 1990, 1992). PQQ biosynthesis most likely takes place in the cytoplasm and PQQ can be released into the medium. Since the PQQ-binding site of GCD faces the periplasm (Yamada et al., 1993b), it is clear that both complementation of $E$. coli with the $K$. pneumoniae pqq genes as well as addition of PQQ can result in an active GCD. From growth studies with $E$. coli ptsHI mutants complemented with the complete set of $K$. pneumoniae $p q q$ genes or with plasmids lacking one of the six $p q q$ genes and from measurement of PQQ biosynthesis in the growth medium, it was concluded that each of the six genes is required for PQQ biosynthesis (Velterop et al., 1995). These results support the conclusion that E. coli as well as S. typhimurium lack the $p q q$ genes.

Unexpectedly, Biville et al. (1991) isolated a mutant of E. coli that seemed to have acquired holo-GCD activity. Starting with a strain that was derived from E. coli FB8 by introducing a ptsHI-crr deletion and a galP:: Tn10 mutation (to eliminate glucose uptake and metabolism via known pathways), a mutant was isolated, EF260, which regained growth on glucose. Presence of PQQ in bacterial cell extracts and conversion of glucose to gluconate was claimed. Although in principle a cryptic $p q q$ operon could be present in $E$. coli, isolation of similar mutants from other $E$. coli strains has proved negative (P.W. Postma, unpublished). We have reexamined this putative $\mathrm{PQQ}^{+} E$. coli strain with respect to its capacity to synthesize PQQ and an active holoGCD and conclude that at present there is no evidence that $E$. coli can synthesize PQQ, even after mutagenesis and that it most likely does not contain $p q q$ genes.

\section{METHODS}

Bacterial strains. The following $E$. coli strains were used: FB8 (prototrophic E. coli K-12 strain); $\Delta$ ptsgal [ $\Delta$ (ptsHI-crr):: Km galP::Tn10, derived from FB8 and renamed PPA322]; EF260 (Glc ${ }^{+}$, derived from $\Delta$ ptsgal) (isolated and described by Biville et al., 1991); PPA533 (gcd::Cm, derived from EF260); and CT690 (recB21 recC22 thi-1 thr-1 leu-6 lacY1 mtl-1 xyl-1 ara14 galK2 bis-4 proA2 arg-63 rpsL31 tsx-33 sup-37 sbcB15, from Dr M. Tsuda, Okayama University, Japan).

Bacterial growth. Strains were pre-cultured in LB medium (w/v: $1 \%$ bactotryptone, $0.5 \%$ yeast extract, $0.5 \% \mathrm{NaCl}$ ). The pre-culture was washed twice with $10 \mathrm{mM}$ potassium phosphate buffer ( $\mathrm{pH} 7.5)$ and resuspended in the same buffer at the same concentration as the original pre-culture. The suspension (inoculum size $5 \%, \mathrm{v} / \mathrm{v}$ ) was then transferred to $100 \mathrm{ml}$ glucose minimal medium (Biville et al., 1991) containing $0.4 \%$ glucose and 21 or $100 \mathrm{mM}$ potassium/sodium phosphate buffer ( $\mathrm{pH} 6.8$ ) and incubated on a rotary shaker (200 r.p.m.) at $30^{\circ} \mathrm{C}$. In a number of cases, cells were grown in a lactate minimal medium containing $100 \mathrm{mM}$ potassium phosphate buffer (Matsushita et al., 1984) as a control. Both PPA322 and EF260 strains were cultivated in the presence of $10 \mu \mathrm{g}$ tetracycline $\mathrm{ml}^{-1}$ and $25 \mu \mathrm{g}$ kanamycin $\mathrm{ml}^{-1}$.

Construction of a genomic gcd disruption mutant. The HincII fragment encoding the chloramphenicol acetyltransferase gene from pMC1 (Close \& Rodriguez, 1982) was inserted into the Smal site of the gcd gene of pUCGCD1 (Yamada et al., 1993a). The resulting plasmid, pUCGCDCM, was digested with SalI and PstI and introduced into CT690. The cells were grown on LB agar containing $10 \mu \mathrm{g}$ chloramphenicol ml $\mathrm{m}^{-1}$. Absence of GCD activity in the chloramphenicol-resistant colonies was tested on glucose-citrate minimal agar plates $[28 \mathrm{mM}$ glucose, $9.5 \mathrm{mM}$ citrate, $25 \mathrm{mM} \mathrm{Na}\left(\mathrm{NH}_{4}\right) \mathrm{HPO}_{4}, 57 \mathrm{mM} \mathrm{K}_{2} \mathrm{HPO}_{4}$, $4 \mathrm{mM} \mathrm{KH}_{2} \mathrm{PO}_{4}, 1.6 \mathrm{mM} \mathrm{MgSO}_{4}, 0.06 \mathrm{mM} \mathrm{FeSO}_{4}, 0.06 \mathrm{mM}$ $\mathrm{MnSO}_{4}, 0.2 \mathrm{mM} \mathrm{NaCl}$ ] containing $0.1 \%$ bromothymol blue and $0.1 \mathrm{mM}$ PQQ. Putative genomic gcd:: Cm mutants, which showed a weak yellow colour on the indicator plate, were subjected to measurement of GCD activity and genomic analysis by PCR. PCR was performed as described previously (Yamada et al., 1993b). The gcd::Cm mutation was transferred into EF260 by P1 transduction, resulting in PPA533. The gene disruption was also confirmed by Western blot analysis (Matsudaira, 1987) using an antibody against the E. coli GCD.

Preparation of membrane fractions. Cells were collected by centrifugation, washed with $50 \mathrm{mM}$ potassium phosphate buffer ( $\mathrm{pH} 7.5$ ) and resuspended in the same buffer at a concentration of $1 \mathrm{~g}$ wet cells per $5 \mathrm{ml}$. After adding a few grains of DNase powder, the suspension was passed twice 
through a French pressure cell at $110 \cdot 4 \mathrm{MPa}$ and centrifuged at $12000 \mathrm{~g}$ for $20 \mathrm{~min}$ to remove intact cells and cell debris. The membranes were precipitated by centrifugation at $120000 \mathrm{~g}$ for $90 \mathrm{~min}$ and homogenized with $50 \mathrm{mM}$ potassium phosphate buffer ( $\mathrm{pH} 7 \cdot 5)$.

Enzyme assays. GCD activity was measured spectrophotometrically at $25^{\circ} \mathrm{C}$ using phenazine methosulfate (PMS) and 2,6-dichlorophenol indophenol (DCIP) as electron acceptors as described by Matsushita et al. (1980) before or after holo-enzyme formation. Holo-enzyme was prepared by incubating the apo-enzyme at $25^{\circ} \mathrm{C}$ for $30 \mathrm{~min}$ in $50 \mathrm{mM}$ potassium phosphate buffer $(\mathrm{pH} 6.5)$ containing $1 \mu \mathrm{M}$ PQQ and $10 \mathrm{mM} \mathrm{MgSO}$. The assay was performed in $50 \mathrm{mM}$ potassium phosphate buffer ( $\mathrm{pH} 6.5$ ) containing $8 \mathrm{mM}$ sodium azide and enzyme activity was calculated using an extinction coefficient of $13.2 \mathrm{mM}^{-1} \mathrm{~cm}^{-1}$ for DCIP. To determine the $K_{\mathrm{m}}$ of GCD for PQQ, membranes or purified GCD were incubated in a medium containing $40 \mathrm{mM}$ potassium phosphate buffer, $30 \mathrm{mM}$ glucose, $6 \mathrm{mM} \mathrm{NaN}_{3}, 10 \mathrm{mM} \mathrm{MgSO}_{4}, 0.4 \mathrm{mM}$ PMS and $0.2 \mathrm{mM}$ DCIP, final $\mathrm{pH} 6.5$. The reaction was started by the addition of various concentrations of $\mathrm{PQQ}$. The reaction rate increased gradually and the activity was calculated from the final steady-state rate.

PQQ determination. PQQ in the culture medium was concentrated by a Sep-Pak Cartridge (C18, Waters) as follows. After the $\mathrm{pH}$ was adjusted with concentrated $\mathrm{HCl}$ to $2 \cdot 0$, the medium supernatant $(90 \mathrm{ml})$ was separated from the cells by centrifugation and was applied to the cartridge, pre-washed with $10 \mathrm{mM} \mathrm{HCl}$. After washing the cartridge with $10 \mathrm{mM}$ $\mathrm{HCl}, \mathrm{PQQ}$ was eluted with $50 \%$ (v/v) methanol. To concentrate PQQ 100-200-fold, the eluted fraction was evaporated to about $0.5 \mathrm{ml}$. PQQ was determined with the use of apo-sGCD (the soluble form of GCD) prepared from an A. calcoaceticus PQQ-deficient mutant (Matsushita et al., 1995). GCD activity was measured as described above after incubating for $5 \mathrm{~min}$ in $0.1 \mathrm{ml}$ of a reaction mixture that contained per $0.25 \mathrm{ml}: 50 \mathrm{mM}$ PIPES/NaOH buffer (pH 6.5), apo-sGCD (approximately $2 \mathrm{ng}$ protein), $3 \mathrm{mM} \mathrm{CaCl}, 0 \cdot 1 \%$ Triton X-100 and the sample or a PQQ standard $(0-0.2 \mathrm{ng})$. The concentration of PQQ was determined from a standard curve prepared with $0-0 \cdot 2 \mathrm{ng} P Q Q$ in the reaction mixture.

Determination of gluconate content. Gluconate content in the culture medium was determined using gluconate dehydrogenase, purified from Pseudomonas aeruginosa (Matsushita et al., 1979), which has a high specificity for gluconate (Matsushita et al., 1982). Gluconate dehydrogenase activity was measured spectrophotometrically at $25^{\circ} \mathrm{C}$ in a reaction mixture which contained $50 \mathrm{mM}$ PIPES/NaOH buffer ( $\mathrm{pH} 6.5$ ), gluconate dehydrogenase (approximately 0.1 unit), $0.4 \mathrm{mM}$ PMS, $0.2 \mathrm{mM}$ DCIP and the sample, obtained from the medium after centrifugation, or a standard gluconate solution $(0-10 \mathrm{mM})$.

Transport and oxidation studies. Cells were grown overnight at $37^{\circ} \mathrm{C}$ on a rotary shaker in minimal medium $\mathrm{A}[1 \mathrm{~g}$ $\left(\mathrm{NH}_{4}\right)_{2} \mathrm{SO}_{4}, 10.5 \mathrm{~g} \mathrm{~K}_{2} \mathrm{HPO}_{4}, 4.5 \mathrm{~g} \mathrm{KH}_{2} \mathrm{PO}_{4}, 1 \mathrm{~g} \mathrm{MgSO}_{4}$ per litre demineralized water] with $0.4 \%$ D,L-lactate as carbon source and $1 \mathrm{mM}$ D-fucose as indicated, diluted tenfold and grown in the same medium and harvested when the $\mathrm{OD}_{600}$ was approximately 0.5 (Hitachi model $100-50$ spectrophotometer). Cells were harvested and washed and transport of ${ }^{14} \mathrm{C}$ carbohydrates was measured as described elsewhere (Postma, 1977). Oxygen consumption was measured with a Clark-type electrode in medium $A$ and expressed as nanoatoms of $\mathrm{O}$ consumed $\min ^{-1}(\mathrm{mg} \text { dry wt })^{-1}$ at $25^{\circ} \mathrm{C}$.

Other procedures. SDS-PAGE, protein determinations, prep- aration of antibodies and immunoblotting analysis were performed as described by Matsushita et al. (1989). E. coli GCD was purified as described by Yamada et al. (1993b).

Materials. PQQ was obtained from Ube Industries. The immunoblotting kit and pre-stained marker proteins were obtained from Bio-Rad. PVDF microporous membrane was purchased from Millipore. D-[U- $\left.{ }^{14} \mathrm{C}\right]$ Glucose $(10.5 \mathrm{GBq}$ $\mathrm{mmol}^{-1}$ ) was obtained from The Radiochemical Centre; $\left[{ }^{14} \mathrm{C}\right]$ methyl- $\beta$-galactopyranoside $\left(1 \cdot 4 \mathrm{GBq} \mathrm{mmol}^{-1}\right)$ and $\mathrm{D}-[\mathrm{U}-$ ${ }^{14} \mathrm{Clgalactose}\left(13 \cdot 2 \mathrm{GBq} \mathrm{mmol}^{-1}\right)$ were purchased from Dupont NEN Research Products.

\section{RESULTS AND DISCUSSION}

\section{Growth behaviour on various media}

To investigate the possibility whether mutations could be isolated in E. coli that resulted in the synthesis of PQQ, Biville et al. (1991) started with a strain that was unable to grow on glucose due to mutations in the phosphoenolpyruvate: carbohydrate phosphotransferase system and in galactose permease $[\Delta(p t s H I-c r r)$ galP::Tn10]. This strain, originally named $\Delta$ ptsgal and renamed PPA322 by us, was derived from the parent strain FB8. EF260 was isolated as a $\mathrm{Glc}^{+}$derivative of PPA322 by Biville et al. (1991) and further analysis led them to conclude that EF260 can synthesize PQQ.

To characterize in more detail the mutation in E. coli EF260 that restored growth on glucose, growth of FB8, PPA322 and EF260 was compared in glucose-minimal medium, containing $0.4 \%$ glucose and $100 \mathrm{mM}$ potassium phosphate buffer. As shown in Fig. 1, EF260 grew faster than its parent, PPA322, but slower than the wild-type strain, FB8. EF260 also showed a prolonged

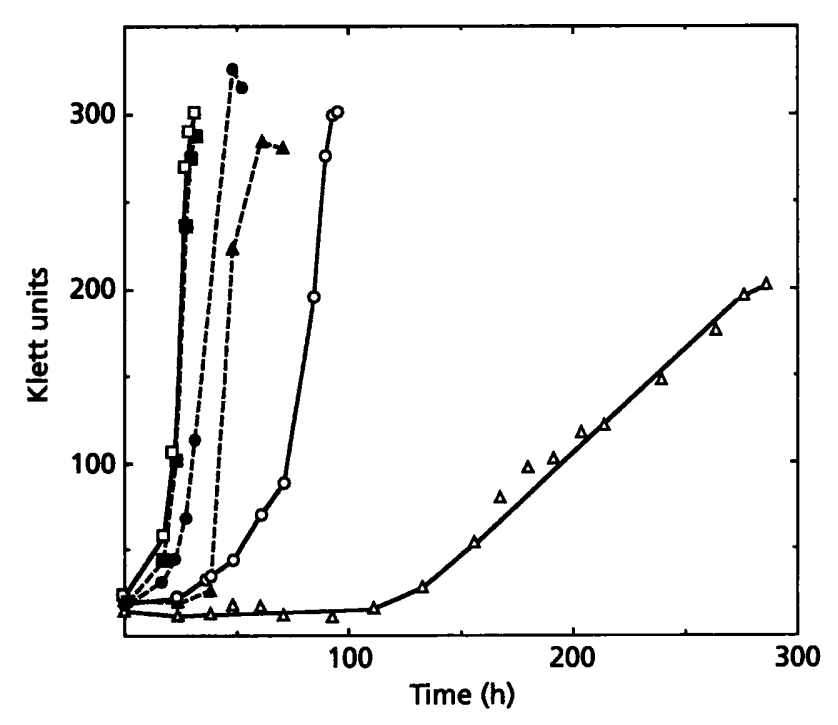

Fig. 1. Growth of E. coli FB8, PPA322 and EF260 in the presence and absence of PQQ. Cells were grown in glucose minimal medium containing $0.4 \%$ glucose and $100 \mathrm{mM}$ potassium/sodium phosphate buffer (as described in Methods). $\square$, FB8; $\square$, FB8+10 nM PQQ; O, EF260; O, EF260+10 nM PQQ; $\triangle$, PPA322; $\triangle$, PPA322+10 nM PQQ. 
Table 1. GCD activities in membranes of $E$. coli FB8, PPA322 and EF260

\begin{tabular}{|c|c|c|c|c|c|c|}
\hline \multirow[t]{3}{*}{ Growth medium } & \multicolumn{6}{|c|}{ GCD activity [units (mg protein) ${ }^{-1}$ ] } \\
\hline & \multicolumn{2}{|c|}{ FB8 } & \multicolumn{2}{|c|}{ PPA322 } & \multicolumn{2}{|c|}{ EF260 } \\
\hline & $-P Q Q$ & $+\mathrm{PQQ}^{*}$ & $-P Q Q$ & $+\mathrm{PQQ}^{*}$ & $-P Q Q$ & $+\mathrm{PQQ}^{*}$ \\
\hline Lactate medium $/ 100 \mathrm{mM} P_{i}$ & 0 & 0.032 & 0.002 & $0 \cdot 142$ & 0.002 & 0.089 \\
\hline Glucose medium/21 $\mathrm{mM} \mathrm{P}$ & 0.002 & $1 \cdot 09$ & 0.003 & $0 \cdot 234$ & 0.002 & 0.347 \\
\hline Glucose medium $/ 100 \mathrm{mM} \mathrm{P_{1 }}$ & 0.003 & $0 \cdot 684$ & 0.001 & $0 \cdot 274$ & 0 & $0 \cdot 156$ \\
\hline Glucose medium $/ 100 \mathrm{mM} \mathrm{P}+10 \mathrm{nM} P Q Q$ & 0.003 & 0.622 & 0.014 & $1 \cdot 12$ & 0.005 & 0.569 \\
\hline
\end{tabular}

* Membranes were pre-incubated with $1 \mu \mathrm{M}$ PQQ and $10 \mathrm{mM} \mathrm{MgSO}_{4}$ before the GCD activity was determined.

lag time. Addition of PQQ increased the growth rate of PPA322 but also of EF260. Qualitatively the same results were obtained when these growth studies were performed with a medium containing $21 \mathrm{mM}$ potassium phosphate buffer, similar to the medium used by Biville et al. (1991). However, in this medium the extent of growth was much smaller in the presence of PQQ, most likely because of acid production (the $\mathrm{pH}$ of these culture media decreased below $\mathrm{pH} 4.0$ under these growth conditions) (data not shown). All three strains grew rapidly and at the same rate in lactate-containing medium (100 $\mathrm{mM} \mathrm{P}_{\mathrm{i}}$ ) (data not shown).

The comparison of the growth properties of PPA322 and EF260 suggests that the addition of PQQ produced an active GCD, even in strain EF260, resulting in the production of gluconic acid and thus in a decreased medium $\mathrm{pH}$, unless a high concentration of buffer was added to the medium. From these data, it can be speculated that neither EF260 nor PPA322 could produce PQQ.

\section{GCD apo-enzyme and holo-enzyme}

Biville et al. (1991) detected a low holo-enzyme GCD activity $\left.[0 \cdot 1-0.3 \text { units (mg protein })^{-1}\right]$ in the glucoseutilizing strain EF260 and proposed that growth on glucose was due to a PQQ-dependent GCD activity. In the present study GCD activity was determined in the membrane fraction of the three strains, grown in three different media : lactate $+100 \mathrm{mM} \mathrm{P}_{1}$, glucose $+21 \mathrm{mM}$ $P_{i}$ and glucose $+100 \mathrm{mM} P_{i}$. As shown in Table 1 , no enzyme activity $\left[<0.01\right.$ units $\left.(\mathrm{mg} \text { protein })^{-1}\right]$ could be detected in any of the three strains grown in three different media. Presence of apo-GCD was detected, however, in the three strains after pre-incubation with cofactor PQQ. The activities of reconstituted holoenzyme GCD were higher in membranes prepared from cells grown on glucose than in the membrane fraction of lactate-grown cells. The enzyme activity of FB8 was relatively high compared to that of PPA322 and EF260, the latter two strains showing almost the same activity. GCD activity was not increased by the addition of $\mathbf{M g}^{2+}$ in the absence of PQQ (data not shown). Interestingly, addition of PQQ to the culture medium seemed to stimulate the expression of GCD in PPA322 and EF260. This was tested only in the medium containing $100 \mathrm{mM}$ $P_{1}$ because acid production disturbed the growth at lower phosphate concentrations, as mentioned above. However, even under these conditions, i.e. growth of cells in a medium containing PQQ, enzyme activity could not be detected. This is probably because high phosphate concentrations disturbed the tight binding of PQQ to the apo-enzyme under the growth conditions. Apparently, GCD apo-enzyme pre-incubated with PQQ is less sensitive to the presence of $P_{i}$. It should be realized, however, that reconstitution of apo-enzyme took place in $50 \mathrm{mM} \mathrm{P} \mathrm{P}_{\mathrm{i}}$ with $1 \mu \mathrm{M}$ PQQ, whereas growth occurred in $100 \mathrm{mM} \mathrm{P}_{\mathrm{f}}$ containing $10 \mathrm{nM}$ PQQ. Although the PQQ concentration in the culture is below the $K_{\mathrm{m}}$ of GCD for PQQ, a low level of holo-enzyme GCD might be sufficient for growth.

We considered the possibility that GCD in EF260 had altered properties, i.e. increased affinity for PQQ which would allow this strain to scavenge PQQ more efficiently from the medium rather than to synthesize it. The protein level of GCD in the membrane fractions was examined by immunoblotting and paralleled the enzyme activity in the membranes (data not shown). In addition, the mobility of the enzyme was identical in the three strains. Furthermore, the affinity of GCD for PQQ was examined with membranes prepared from the various strains. GCDs in the membranes from the three different types of cells showed the same apparent $K_{\mathrm{m}}$ values as those of the purified enzyme (Table 2). Thus, both the structure and the function of GCD in the mutant strains, E. coli PPA322 and EF260, did not seem to be changed compared to those of the wild-type strain and an increased capacity to scavenge PQQ seemed unlikely.

\section{PQQ and gluconate production in the various $E$. coli strains}

To establish whether or not $E$. coli strains, including the mutants, were able to produce PQQ and whether, as a result, holo-GCD occurred in these cells, the PQQ and gluconate concentration were determined in the culture medium. To determine the PQQ content, a highly sensitive PQQ assay system was developed using apo- 
Table 2. Affinity of GCD for PQQ in membranes

\begin{tabular}{|c|c|c|c|c|}
\hline \multirow{2}{*}{$\begin{array}{l}\text { GCD fraction } \\
\text { Purified GCD* }\end{array}$} & \multirow{2}{*}{ Growth condition } & \multicolumn{3}{|c|}{$\begin{array}{c}K_{\mathrm{m}}(\mathrm{PQQ}) \\
(\mathrm{nM})\end{array}$} \\
\hline & & 44 & and & 111 \\
\hline Membranes FB8 & Lactate medium/100 $\mathrm{mM} P_{1}$ & 40 & and & 100 \\
\hline Membranes FB8 & Glucose medium $/ 21 \mathrm{mM} P_{1}$ & 40 & and & 100 \\
\hline Membranes PPA322 & Lactate medium $/ 100 \mathrm{mM} \mathrm{P_{1 }}$ & 40 & and & 100 \\
\hline Membranes EF260 & Lactate medium/100 $\mathrm{mM} \mathrm{P}_{1}$ & 42 & and & 111 \\
\hline Membranes EF260 & Glucose medium $/ 21 \mathrm{mM} \mathrm{P}_{1}$ & 33 & and & 109 \\
\hline Membranes EF260 & Glucose medium $/ 100 \mathrm{mM} \mathrm{P}$ & 33 & and & 86 \\
\hline
\end{tabular}

${ }^{*}$ E. coli GCD was purified as described in Methods.

Table 3. PQQ concentration in culture media of E. coli FB8, PPA322 and EF260

Cells were grown to early stationary phase. At the time indicated, the cultures were centrifuged to remove the cell pellets. The supernatant was used for measuring the PQQ content. PPA322 was also grown up with the prolonged lag time as shown originally by Biville et al. (1991). Unless indicated otherwise, values represent the mean of at least two independent determinations ( \pm SEM).

\begin{tabular}{|llcl|}
\hline Strain & Medium condition & Cultivation time $(\mathbf{h})$ & PQQ (nM) \\
\hline Control & $100 \mathrm{mM} \mathrm{P}_{1}$ & - & $0.021 \pm 0.005$ \\
FB8 & $100 \mathrm{mM} \mathrm{P}_{1}$ & 27 & $0.025 \pm 0.009$ \\
FB8 & $100 \mathrm{mM} \mathrm{P}_{1} / 10 \mathrm{nM} \mathrm{PQQ}$ & 27 & $8.3(n=1)$ \\
PPA322 & $100 \mathrm{mM} \mathrm{P}_{1}$ & 286 & $0.018(n=1)$ \\
EF260 & $100 \mathrm{mM} \mathrm{P}_{1}$ & 95 & $0.021 \pm 0.002$ \\
\hline
\end{tabular}

GCD (soluble form) purified from an A. calcoaceticus PQQ-deficient mutant (Matsushita et al., 1995). The apo-enzyme was able to detect $0.01-0.4 \mathrm{ng}$ of PQQ in the assay system, as described in Methods. Thus, we could detect PQQ in the culture medium at the level of $1 \mathrm{pM}$. As shown in Table 3, the original culture medium without any bacterial cells added, contained $0.021 \mathrm{nM}$ PQQ. After growth of the cells, the culture medium contained only slightly higher concentrations of $P Q Q$ in all cases. Only in the case of EF260 growing in a medium containing $20 \mathrm{mM} \mathrm{P}$ was a somewhat higher PQQ concentration found, for unknown reasons, but even in this case the level was very low. Recovery of most PQQ added to the growth medium with FB8 shows that PQQ could be detected in this medium. We conclude that none of the three E. coli strains, including EF260, could produce PQQ.

If glucose metabolism in EF260 utilized a PQQ-dependent GCD pathway, gluconate production would be expected. The gluconate content of the culture medium was determined. In the absence of PQQ, all three strains produced only $0.015-0.020 \mathrm{mM}$ gluconate in the culture medium containing $20 \mathrm{mM} \mathrm{P}$ or no gluconate at all in a medium containing $100 \mathrm{mM} \mathrm{P}$. Thus, EF260 was unable to produce gluconate, even though glucose metabolism is supposed to involve the PQQ-dependent GCD pathway in this strain. The effect of the addition of PQQ was tested to verify that in the presence of genuine PQQ gluconate was indeed produced, although the strains did not grow well in a medium containing $20 \mathrm{mM} \mathrm{P} \mathrm{P}_{\mathrm{i}}$ and PQQ (because of acid production, see above). Both PPA322 and EF260 produced 1.4-2.4 mM gluconate in the PQQ-containing medium. On the other hand, in the cultures containing $100 \mathrm{mM} \mathrm{P}$, no gluconate production could be detected (only 1-3 $\mu \mathrm{M}$ ) even in the presence of $P Q Q$, despite the fact that growth under these conditions was normal. This may be caused by the slow production and relatively fast utilization of gluconate in the cultures that contain a high $\mathrm{P}_{1}$ and $\mathrm{PQQ}$ concentration.

Since both the buffer capacity and the phosphate concentration were expected to be important for growth and the formation of holo-enzyme, gluconate production was examined in more detail with EF260 in the absence and presence of PQQ in a glucose minimal medium containing either $32 \mathrm{mM} \mathrm{P}$ (Fig. $2 \mathrm{a}$ ) or $32 \mathrm{mM}$ $\mathrm{P}_{\mathrm{i}}+50 \mathrm{mM}$ MOPS buffer (Fig. 2b). Gluconate accumulated to high levels at the early to mid-exponential phase in the cultures containing PQQ, ranging from 10 to $15 \mathrm{mM}$. However, in the absence of PQQ, almost no gluconate formation $(5-60 \mu \mathrm{M})$ was observed.

It is concluded that $E$. coli strains, even the EF260 strain, were unable to produce PQQ in their culture medium. Although the reason is unclear, high phosphate levels in the growth medium may prevent the interaction between apo-GCD and PQQ. As a consequence, these strains may not have any holo-GCD, required for the production of gluconate, even when PQQ was added to the medium. 


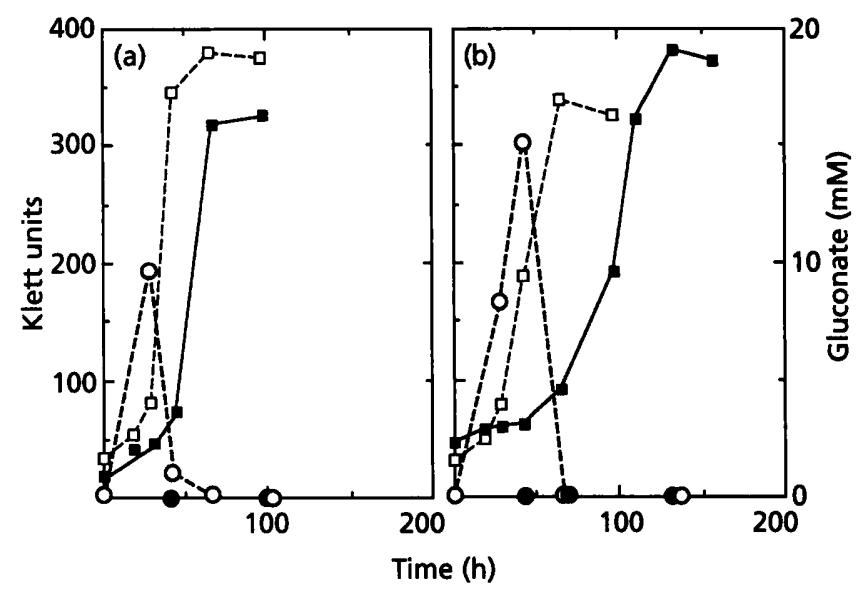

Fig. 2. Gluconate production by $E$. coli EF260 in the presence and absence of PQQ. EF260 was grown in glucose-minimal medium containing $32 \mathrm{mM}$ potassium/sodium phosphate buffer (a) or the same phosphate buffer plus 50 mM MOPS, pH 7.0 (b). $\square, \square$, growth curves; $O$, gluconate concentration in the culture media; $\square$, O, with $10 \mathrm{nM}$ PQQ; $\square$, without PQQ.

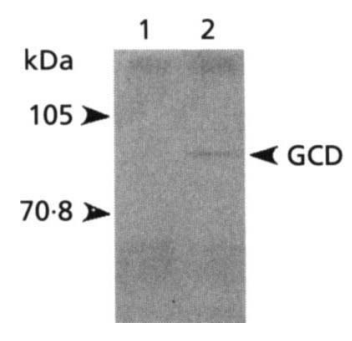

Fig. 3. Western blot analysis of the gcd::Cm mutant PPA533 and its parent EF260. Membrane fractions ( $20 \mu \mathrm{g}$ protein) of PPA533 (lane 1) and EF260 (lane 2) were analysed by $8 \%$ SDSPAGE, blotted on PVDF membrane and detected with a polyclonal antibody against GCD.

\section{Role of GCD in the phenotype of $E$. coli EF260}

Although after growth on glucose no GCD holo-enzyme activity could be detected in EF260, nor gluconate formation, we have investigated whether deletion of the gcd gene would affect the $\mathrm{Glc}^{+}$phenotype of EF260, as predicted if the PQQ/GCD pathway was active. Fig. 3 shows that introduction of the $g c d:: \mathrm{Cm}$ mutation in EF260 eliminated GCD in PPA533 completely. Growth of PPA533 on glucose was not impaired, however, compared to that of EF260. It is concluded that growth of EF260 on glucose is not dependent on the PQQ/GCD pathway.

\section{Uptake and oxidation of glucose}

EF260 was originally selected as a strain able to grow on glucose. Its parent, PPA322 $[\Delta(p t s H I-c r r)$ galP $]$ is lacking known glucose transporters and cannot grow on glucose. Since we have demonstrated that, in contrast to earlier conclusions, the GCD/PQQ pathway is not active in EF260, the question arises how glucose is taken up and metabolized. Possibly, the galP mutation had reverted and the galactose permease, GalP, had become constitutive. Alternatively, the $\beta$-methylgalactoside permease (MglP) might have become active. Both transport systems, when expressed constitutively, can catalyse glucose uptake.

Table 4 shows that uptake of glucose, galactose or $\beta$ methylgalactoside was very low in PPA322, as expected since the strain lacks both the phosphoenolpyruvate: carbohydrate phosphotransferase system as well as the GalP. In addition, it has been shown previously that synthesis of MglP is prevented in $\Delta$ ptsHI strains due to the low cAMP level (Postma et al., 1981). Uptake of the three substrates, including glucose, was not increased in the $\mathrm{Glc}^{+}$strain, EF260. Thus, no constitutive glucose transport system had evolved in EF260. Growth in the presence of the gratuitous inducer D-fucose resulted in some induction of the MglP system in both strains. The absence of GalP could also be concluded from the observation that the strains were still resistant to 2deoxygalactose (Henderson \& Giddens, 1977; Nagelkerke \& Postma, 1978).

The transport studies showed that none of the known glucose transporters was active in EF260. These transporters have quite high apparent affinity for glucose, ranging from 1 to $100 \mu \mathrm{M}$. Conceivably, a low-affinity glucose uptake system could be present. By measuring glucose oxidation with isolated cells grown in LB in the presence of $1 \%$ glucose, an apparent affinity for glucose of $15 \mathrm{mM}$ could be determined. Cells grown in LB or a minimal salts medium containing lactate, displayed an apparent $K_{m}$ in the same range. The $V_{\max }$ of oxygen uptake was 174 and 78 nanoatoms $O$ taken up $\min ^{-1}$ $(\mathrm{mg} \text { dry wt })^{-1}$ for cells grown on LB and LB + glucose, respectively. Thus, no evidence could be found for a high-affinity glucose uptake system.

\section{Conclusions}

The conclusion by Biville et al. (1991) that E. coli can synthesize PQQ is most likely erroneous. The following observations with E. coli EF260 support this statement. (i) E. coli EF260 was unable to synthesize a holo-enzyme GCD unless PQQ was supplied to the growth medium. No GCD activity could be detected in membrane fractions. (ii) The amount of PQQ detected in EF260 was not very different from that of its parent and from the amount found in the growth medium in the absence of cells. (iii) EF260 was unable to produce gluconate via the PQQ/GCD pathway. (iv) Introduction of a $g c d:: \mathrm{Cm}$ deletion, eliminating GCD, did not affect glucose metabolism in EF260. This suggested a pathway for glucose metabolism other than the PQQ/GCD pathway. (v) Since EF260 was isolated from its parent (PPA322) as a mutant that regained growth on glucose, an alternative glucose-metabolizing pathway must have been created which was different from the GCD/PQQ pathway. Glucose uptake and metabolism in EF260 involved a low-affinity transport system of unknown identity, 
Table 4. Uptake of labelled carbohydrates

Strains were grown in minimal medium containing lactate and, where indicated, $1 \mathrm{mM}$ D-fucose.

Cells were harvested and uptake of labelled substrates was measured as described in Methods using $0.5 \mathrm{mM}\left[{ }^{14} \mathrm{C}\right]$ glucose, $0.5 \mathrm{mM}\left[{ }^{14} \mathrm{C}\right]$ galactose or $0.5 \mathrm{mM} \beta-\left[{ }^{14} \mathrm{C}\right]$ methylgalactoside.

\begin{tabular}{|lcccc|}
\hline \multirow{2}{*}{ Strain } & D-Fucose & \multicolumn{3}{c|}{ Rate of uptake* } \\
\cline { 3 - 5 } & & Galactose & $\boldsymbol{\beta}$-Methylgalactoside & Glucose \\
\hline PPA322 & - & 0.2 & 0.3 & 0.1 \\
PPA322 & + & 1.9 & 4.1 & 1.5 \\
EF260 & - & 0.3 & 0.3 & 0.7 \\
EF260 & + & 0.6 & 1.1 & 0.7 \\
\hline
\end{tabular}

* Activity is expressed as nmol carbohydrate taken up $\min ^{-1}(\mathrm{mg} \text { dry } w \mathrm{t})^{-1}$ at $20^{\circ} \mathrm{C}$.

followed most likely by phosphorylation via glucokinase.

Two other observations have to be explained. It was recently reported that an $E$. coli DNA fragment could complement pqqE/F mutants of Methylobacterium organophilum (Turlin et al., 1996). The ORF responsible, orf106, most likely encodes a $K$. pneumoniae PqqF-like protease that can complement the defect in $M$. organophilum. A similar suggestion has been made concerning the complementation of a defective $K$. pneumoniae $p q q F$ gene product by an $E$. coli protease (Velterop et al., 1995). The finding that an Erwinia berbicola DNA fragment, claimed to contain a $p q q E$ like gene but no other PQQ genes, was sufficient for gluconate production from glucose adds weight to the argument that other $p q q$ genes might be present in $E$. coli (Liu et al., 1992). However, the cloned fragment contained a number of $p q q$ genes rather than only the pqqE-like gene (P. W. Postma \& A. H. Goldstein, unpublished observations). Thus, no evidence is available for the presence of $p q q$ genes in E. coli. Our conclusion that $E$. coli is unable to produce PQQ is supported by the fact that the recently completed nucleotide sequence of the $E$. coli genome contained no ORFs that could encode proteins with similarity to other PQQ proteins.

\section{ACKNOWLEDGEMENTS}

We would like to thank Michiko Maeyama, Masami Yokoo and Kenichi Sumi for technical assistance. This work was supported in part by Grant-in-aids 06660113 for scientific research from the Ministry of Education, Science, and Culture, Japan (to K.M.).

\section{REFERENCES}

Ameyama, M., Nonobe, M., Shinagawa, E., Matsushita, K., Takimoto, K. \& Adachi, O. (1986). Purification and characterization of the quinoprotein D-glucose dehydrogenase apoenzyme from Escherichia coli. Agric Biol Chem 50, 49-57.

Biville, F., Turlin, E. \& Gasser, F. (1991). Mutants of Escherichia coli producing pyrroloquinoline quinone. J Gen Microbiol 137, 1775-1782.
Close, T. J. \& Rodriguez, R. L. (1982). Construction and characterization of the chloramphenicol-resistance gene cartridge: a new approach to the transcriptional mapping of extrachromosomal elements. Gene 20, 305-316.

Duine, J. A. (1991). Quinoproteins: enzymes containing the quinonoid cofactor pyrroloquinoline quinone, topaquinone or tryptophan-tryptophan quinone. Eur J Biochem 200, 271-284.

Goosen, N., Horsman, H. P. A., Huinen, R. G. M. \& van de Putte, P. (1989). Acinetobacter calcoaceticus genes involved in biosynthesis of the coenzyme pyrroloquinoline-quinone: nucleotide sequence and expression in Escherichia coli K-12. J Bacteriol 171, $447-455$.

Goosen, N., Huinen, R. G. M. \& van de Putte, P. (1992). A 24amino-acid polypeptide is essential for the biosynthesis of the coenzyme pyrrolo-quinoline-quinone. J Bacteriol 174, 1426-1427.

Henderson, P. J. F. \& Giddens, R. A. (1977). 2-Deoxygalactose, a substrate for the galactose-transport system of Escherichia coli. Biochem J 168, 15-22.

Hommes, R. W. J., Postma, P. W., Neijssel, O. M., Tempest, D. W., Dokter, P. \& Duine, J. A. (1984). Evidence for a glucose dehydrogenase apo-enzyme in several strains of Escherichia coli. FEMS Microbiol Lett 24, 329-333.

Hommes, R. W. J., Loenen, W. A. M., Neijssel, O. M. \& Postma, P. W. (1986). Galactose metabolism in gal mutants of Salmonella typhimurium and Escherichia coli. FEMS Microbiol Lett 36, 187-190.

Houck, D. R., Hanners, J. L. \& Unkefer, C. J. (1988). Biosynthesis of pyrroloquinoline quinone. 1. Identification of biosynthetic precursors using ${ }^{13} \mathrm{C}$ labeling and NMR spectroscopy. J Am Chem Soc 110, 6920-6921.

Houck, D. R., Hanners, J. L. \& Unkefer, C. J. (1991). Biosynthesis of pyrroloquinoline quinone. 2. Biosynthetic assembly from glutamate and tyrosine. J Am Chem Soc 113, 3162-3166.

Klinman, J. P. (1996). New quinocofactors in eukaryotes. J Biol Chem 271, 27189-27192.

Klinman, J. P. \& Mu, D. (1994). Quinoenzymes in biology. Annu Rev Biochem 63, 299-344.

Liu, S.-T., Lee, L.-Y., Tai, C.-Y., Hung, C.-H., Chang, Y.-S., Wolfram, J. H., Rogers, R. \& Goldstein, A. H. (1992). Cloning of an Erwinia berbicola gene necessary for gluconic acid production and enhanced mineral phosphate solubilization in Escherichia coli HB101: nucleotide sequence and probable involvement in biosynthesis of the coenzyme pyrroloquinoline quinone. J Bacteriol 174, 5814-5819. 
Matsudaira, P. (1987). Sequence from picomole quantities of proteins electroblotted onto polyvinylidene difluoride membranes. J Biol Chem 262, 10035-10038.

Matsushita, K. \& Adachi, O. (1993). PQQ, a growth-stimulating substance for microorganisms. In Principles and Applications of Quinoproteins, pp. 355-364. Edited by V. L. Davidson. New York: Marcel Dekker.

Matsushita, K., Shinagawa, E., Adachi, O. \& Ameyama, M. (1979). Membrane-bound D-gluconate dehydrogenase from Pseudomonas aeruginosa. Purification and structure of cytochromebinding form. $J$ Biochem 85, 1173-1181.

Matsushita, K., Ohno, Y., Shinagawa, E., Adachi, O. \& Ameyama, M. (1980). Membrane-bound D-glucose dehydrogenase from Pseudomonas sp: solubilization, purification and characterization. Agric Biol Chem 44, 1505-1512.

Matsushita, K., Shinagawa, E. \& Ameyama, M. (1982). DGluconate dehydrogenase from bacteria, 2-keto-D-gluconate yielding, membrane-bound. Methods Enzymol 89, 187-193.

Matsushita, K., Patel, L. \& Kaback, H. R. (1984). Cytochrome o type oxidase from Escherichia coli. Characterization of the enzyme and mechanism of electrochemical proton gradient generation. Biochemistry 23, 4703-4714.

Matsushita, K., Shinagawa, E., Adachi, O. \& Ameyama, M. (1989). Quinoprotein D-glucose dehydrogenase of the Acinetobacter calcoaceticus respiratory chain: membrane-bound and soluble forms are different molecular species. Biochemistry 28, 6276-6280.

Matsushita, K., Toyama, H., Ameyama, M., Adachi, O., Dewanti, A. \& Duine, J. A. (1995). Soluble and membrane-bound quinoprotein D-glucose dehydrogenase of the Acinetobacter calcoaceticus; the binding process of PQQ to the apoenzymes. Biosci Biotech Biochem 59, 1548-1555.

Meulenberg, J. J. M., Sellink, E., Loenen, W. A. M., Riegman, N. H., van Kleef, M. \& Postma, P. W. (1990). Cloning of Klebsiella pneumoniae pqq genes and PQQ biosynthesis in Escherichia coli. FEMS Microbiol Lett 71, 337-344.

Meulenberg, J. J. M., Sellink, E., Riegman, N. H. \& Postma, P. W. (1992). Nucleotide sequence and structure of the Klebsiella pneumoniae pqq operon. Mol Gen Genet 232, 284-294.

Morris, C. J., Biville, F., Turlin, E., Lee, E., Ellermann, K., Fan, W.-H., Ramamoorthi, R., Springer, A. L. \& Lidstrom, M. E. (1994). Isolation, phenotypic characterization, and complementation analysis of mutants of Methylobacterium extorquens AM1 unable to synthesize pyrroloquinoline quinone and sequences of $p q q D$, $p q q G$, and $p q q C$. J Bacteriol 176, 1746-1755.

Nagelkerke, F. \& Postma, P. W. (1978). 2-Deoxygalactose, a specific substrate of the Salmonella typhimurium galactose permease : its use for the isolation of galP mutants. J Bacteriol 133, $607-613$.
Neijssel, O. M., Tempest, D. W., Postma, P. W., Duine, J. A. \& Frank, J., Jzn (1983). Glucose metabolism by $\mathrm{K}^{+}$-limited Klebsiella aerogenes, evidence for the involvement of a quinoprotein glucose dehydrogenase. FEMS Microbiol Lett 20, 35-39.

Postma, P. W. (1977). Galactose transport in Salmonella typhimurium. J Bacteriol 129, 630-639.

Postma, P. W., Schuitema, A. \& Kwa, C. (1981). Regulation of methyl $\beta$-galactoside permease activity in $p t s$ and $\mathrm{crr}$ mutants of Salmonella typhimurium. Mol Gen Genet 181, 448-453.

Schnider, U., Keel, C., Voisard, C., Défago, G. \& Haas, D. (1995). Tn5-directed cloning of $p q q$ genes from Pseudomonas fluorescens CHA0: mutational inactivation of the genes results in overproduction of the antibiotic pyoluteorin. Appl Environ Microbiol 61, 3856-3864.

Springer, A. L., Ramamoorthi, R. \& Lidstrom, M. E. (1996). Characterization and nucleotide sequence of $p q q E$ and $p q q F$ in Methylobacterium extorquens AM1. J Bacteriol 178, $2154-2157$.

Toyama, H., Chistoserdova, L. \& Lidstrom, M. E. (1997). Sequence analysis of $p q q$ genes required for biosynthesis of pyrroloquinoline quinone in Metbylobacterium extorquens AM1 and the purification of a biosynthetic intermediate. Microbiology 143, 595-602.

Turlin, E., Gasser, F. \& Biville, F. (1996). Sequence and functional analysis of an Escherichia coli DNA fragment able to complement $p q q E$ and $p q q F$ mutants from Methylobacterium organophilum. Biochimie 78, 822-831.

Van Kleef, M. A. G. \& Duine, J. A. (1988). L-Tyrosine is the precursor of PQQ biosynthesis in Hyphomicrobium X. FEBS Lett 237, 91-97.

Van Schie, B. J., de Mooy, O. H., Linton, J. D., van Dijken, J. P. \& Kuenen, J. G. (1987). PQQ-dependent production of gluconic acid by Acinetobacter, Agrobacterium and Rhizobium species. J Gen Microbiol 133, 867-875.

Velterop, J. S. (1995). The biosynthesis of PQQ in Klebsiella pneumoniae. $\mathrm{PhD}$ thesis, University of Amsterdam.

Velterop, J. S., Sellink, E., Meulenberg, J. J. M., David, S., Bulder, I. \& Postma, P. W. (1995). Synthesis of pyrroloquinoline quinone in vivo and in vitro and detection of an intermediate in the biosynthetic pathway. J Bacteriol 177, 5088-5098.

Yamada, M., Asaoka, S., Saier, M. H. \& Yamada, Y. (1993a). Characterization of the gcd gene from Escherichia coli K-12 W3110 and its expression regulation. $J$ Bacteriol 175, 568-571.

Yamada, M., Sumi, K., Matsushita, K., Adachi, O. \& Yamada, Y. (1993b). Topological analysis of quinoprotein glucose dehydrogenase in Escherichia coli and its ubiquinone-binding site. $J$ Biol Chem 268, 12812-12817.

Received 28 April 1997; revised 2 June 1997; accepted 24 June 1997. 